\title{
Гендерные различия в предпринимательстве сферы сервиса национальных экономик
}

\author{
Пиньковецкая Ю.С. \\ Ульяновский государственный университет, \\ Россия, 432000, г. Ульяновск, ул. Л. Толстого, 42 \\ E-mail: judy54@yandex.ru
}

\begin{abstract}
Аннотация. Статья посвящена актуальной проблеме развития сферы услуг в современных национальных экономиках. Целью исследования является оценка уровней специализации фирм, созданных предпринимателями в сервисных видах экономической деятельности. При этом рассматриваются предпринимательские структуры в таких видах деятельности, как финансовые, профессиональные, административные, потребительские и социальные услуги, а также здравоохранение и образование. Процесс исследования включал пять этапов. В качестве исходной информации в исследовании использовались результаты опросов взрослых людей, проведенных в 59 странах, в процессе реализации проекта Глобального мониторинга предпринимательства. В исследовании были решены задачи оценки значений показателей, характеризующих удельные веса мужчин и женщин, создавших бизнесы в сфере услуг по данным за 2018 год, в общей численности соответствующих гендерных страт. Исследование основывалось на разработке экономико-математических моделей. При этом в большинстве стран показано наличие гендерного разрыва. Приведенные в статье выводы обладают существенной новизной и оригинальностью. Они могут быть использованы в деятельности органов государственного управления, а также в дальнейших исследованиях.
\end{abstract}

Ключевые слова: предприниматели, услуги, мужчины, женщины, отраслевая специализация.

Для цитирования: Пиньковецкая Ю.С. 2021. Гендерные различия в предпринимательстве сферы сервиса национальных экономик. Экономика. Информатика, 48 (2): 264-273. DOI 10.52575/2687-09322021-48-2-264-273.

\section{Gender differences in entrepreneurship in the service sector and the economy}

\author{
Iuliia S. Pinkovetskaia \\ Ulyanovsk State University, 42 L. Tolstogo St, Ulyanovsk, 432000, Russia \\ E-mail: judy54@yandex.ru
}

\begin{abstract}
The article is devoted to the actual problem of the development of the service sector in modern national economies. The aim of the study is to assess the levels of specialization of firms created by entrepreneurs in service types of economic activity. In this case, the authors consider business structures in such types of activities as financial, professional, administrative, consumer and social services, as well as health and education. The research process included five stages. As a starting point, the study used the results of surveys of adults conducted in 59 countries during the implementation of the Global Entrepreneurship Monitoring project. The study solved the problem of assessing the values of indicators that characterize the proportion of men and women who have created businesses in the service sector according to data for 2018, in the total number of relevant gender strata. The study was based on the development of economic and mathematical models. At the same time, most countries show the presence of a gender gap. The conclusions presented in the article have a significant novelty and originality. They can be used in the activities of public administration bodies, as well as in further research.
\end{abstract}

Keywords: entrepreneurs, services, men, women, industry specialization. 
For citation: Pinkovetskaia I.S. 2021. Gender differences in entrepreneurship in the service sector and the economy. Economics. Information technologies, 48 (2): 264-273. (in Russian). DOI 10.52575/2687-09322021-48-2-264-273.

\section{Введение}

С началом двадцать первого века в большинстве экономически развитых и развивающихся стран существенно ускорился процесс структурных изменений в экономике, связанный с возрастанием доли сферы сервиса [Castaldi, 2009; Eichengreen, Gupta, 2009]. В связи с этим проблема развития предпринимательства, обеспечивающего выполнение разнообразных услуг, стала одной из наиболее актуальных в современных научных исследованиях.

Рассмотрим некоторые наиболее интересные зарубежные публикации, посвященные указанной проблеме. Общие принципы и концепции сервисной предпринимательской деятельности представлены в монографии [Cuadrado, 2013]. В ней в частности выделены две основные группы фирм, осуществляющих оказание услуг. К первой группе относятся фирмы, специализированные на финансовых, профессиональных, административных и потребительских услугах. Ко второй группе относятся частные организации здравоохранения, образования, а также оказывающие социальные услуги. В работах [Castillo et al., 2014; Fuentes, 2005] анализируется развитие услуг в различных регионах Мексики, при этом отмечается влияние роста объемов оказываемых услуг на сокращение разрыва в экономике этих регионов. Исследования [June, Khar, 2014; Cruz, Delfina, 2004] показывают, что именно предприятия сферы услуг обеспечивают наибольший вклад в рост рабочих мест.

Ряд научных публикаций был посвящен конкретным видам деятельности в сфере услуг. Так, особенности оказания профессиональных услуг были рассмотрены в работе [Nordenflycht, 2010]. Анализ некоторых аспектов предпринимательства в здравоохранении приведен в статье [Black, et al., 2011]. В исследовании [Liao, 2020] рассматриваются вопросы наращивания в последние годы объемов предоставляемых предпринимателями потребительских услуг в Китае. Специализация фирм на социальной работе демонстрируется в работе [Spatscheck, 2019]. Развитие малых предприятий, осуществляющих выполнение финансовых операций для физических лиц, живущих в развивающихся странах, изучено в статье [Mugwati et al., 2013].

Учитывая возрастание роли гендерных исследований в предпринимательстве [Chhabra, Karmarkar, 2016; Grosser, Moon, 2019; Sperber, Linder, 2018], наряду с межстрановым анализом в настоящей статье рассматриваются сложившиеся различия в создании сервисных бизнесов женщинами и мужчинами [Aidis, Weeks, 2016; Jennings, Brush, 2013].

Необходимо отметить, что в выполненных ранее научных исследованиях проблеме гендерных особенностей, характерных для фирм, специализированных на оказании услуг в различных странах, уделялось недостаточно внимания.

\section{Методика исследования}

Цель исследования - оценка уровней специализации фирм, созданных предпринимателями (женщинами и мужчинами) в сервисных видах экономической деятельности в современных странах. При этом рассматриваются указанные ранее две основные группы фирм. К первой группе относятся фирмы, оказывающие финансовые, профессиональные, административные и потребительские услуги. Ко второй группе относятся фирмы в здравоохранении, образовании, а также оказывающие социальные услуги. Процесс исследования включал пять этапов. На первом этапе формировались исходные данные, описывающие создание женщинами и мужчинами бизнесов в сфере услуг по различным странам. На втором этапе оценивались значения удельных показателей, характеризующих создание таких бизнесов женщинами и мужчинами, в общей численности соответствующих 
гендерных страт предпринимателей. На третьем этапе определялись средние значения указанных показателей по рассматриваемым странам и диапазоны, в которых находятся значения этих показателей для большинства из них. На четвертом этапе проводился компаративный анализ, в процессе которого устанавливались страны, в которых отмечались минимальные и максимальные значения показателей. На пятом этапе проводился сравнительный анализ значений показателей по России и зарубежным странам.

В качестве исходной информации в исследовании использовались результаты опросов, проведенных в 59 странах, в процессе реализации проекта Глобального мониторинга предпринимательства [Global Entrepreneurship Monitor, 2019]. Опросы не менее двух тысяч предпринимателей (18-64 лет) в каждой из этих стран позволили получить данные об их специализации на предоставлении услуг.

В нашем исследовании рассматривалась оценка шести показателей, характеризующих создание бизнесов женщинами и мужчинами в сельскохозяйственной и добывающей, а также обрабатывающей и транспортной отраслях по 59 странам в 2018 году. К этим показателям относятся:

- удельный вес женщин, создавших фирмы по оказанию финансовых, профессиональных, административных и потребительских услуг, в общей численности начавших предпринимательскую деятельность женщин, (показатель 1);

- удельный вес мужчин, создавших фирмы по оказанию финансовых, профессиональных, административных и потребительских услуг, в общей численности начавших предпринимательскую деятельность мужчин, (показатель 2);

- отношение значений показателей, характеризующих удельные веса женщин и мужчин, создавших фирмы по оказанию финансовых, профессиональных, административных и потребительских услуг, (показатель 3);

- удельный вес женщин, создавших фирмы по оказанию услуг в здравоохранении и образовании, а также социальных услуг, в общей численности начавших предпринимательскую деятельность женщин (показатель 4);

- удельный вес мужчин, создавших фирмы по оказанию услуг в здравоохранении и образовании, а также социальных услуг, в общей численности начавших предпринимательскую деятельность мужчин, (показатель 5);

- отношение значений показателей, характеризующих удельные веса женщин и мужчин, создавших фирмы по оказанию услуг в здравоохранении и образовании, а также социальных услуг, (показатель 6).

Проведенное исследование включало проверку пяти следующих гипотез:

- гипотеза 1 - в большинстве стран имеют место гендерные различия в удельных весах женщин и мужчин, создавших фирмы по оказанию финансовых, профессиональных, административных и потребительских услуг;

- гипотеза 2 - в большинстве стран имеют место гендерные различия в удельных весах женщин и мужчин, создавших фирмы по оказанию услуг в здравоохранении и образовании, а также социальных услуг;

- гипотеза 3 - значения рассматриваемых шести показателей имеют существенную дифференциацию по разным странам;

- гипотеза 4 - территориальное расположение стран не оказывает существенного влияния на значения каждого из шести показателей;

- гипотеза 5 - уровень доходов населения в рассматриваемых странах не оказывает существенного влияния на значения каждого из шести показателей.

В экономико-математическом моделировании, используемом для оценки каждого из шести показателей, применялись функции нормального распределения. В статье автора [Pinkovetskaia, Slepova, 2018] представлен методический подход к их разработке и использованию для определения средних значений показателей по рассматриваемым государствам, а также диапазонов вариации значений по большинству государств. В процессе нашей работы устанавливались государства с максимальными и минимальными величинами показателей. 


\section{Результаты и обсуждение результатов}

В процессе вычислительного эксперимента проводилось экономико-математическое моделирование на основе эмпирических данных. Модели, которые описывают распределения шести показателей по 59 странам, продемонстрированы далее:

- удельный вес женщин, создавших фирмы по оказанию финансовых, профессиональных, административных и потребительских услуг, в общей численности начавших предпринимательскую деятельность женщин, \%

$$
y_{1}\left(x_{1}\right)=\frac{491,67}{10,49 \times \sqrt{2 \pi}} \cdot e^{-\frac{\left(x_{1}-15,14\right)^{2}}{2 \times 10,49 \times 10,49}}
$$

- удельный вес мужчин, создавших фирмы по оказанию финансовых, профессиональных, административных и потребительских услуг, в общей численности начавших предпринимательскую деятельность мужчин, \%

$$
y_{2}\left(x_{2}\right)=\frac{368,75}{9,63 \times \sqrt{2 \pi}} \cdot e^{-\frac{\left(x_{2}-16,96\right)^{2}}{2 \times 9,63 \times 9,63}} ;
$$

- отношение значений показателей, характеризующих удельные веса женщин и мужчин, создавших фирмы по оказанию финансовых, профессиональных, административных и потребительских услуг

$$
y_{3}\left(x_{3}\right)=\frac{23,61}{0,48 \times \sqrt{2 \pi}} \cdot e^{-\frac{\left(x_{3}-0,91\right)^{2}}{2 \times 0,48 \times 0,48}}
$$

- удельный вес женщин, создавших фирмы по оказанию услуг в здравоохранении и образовании, а также социальных услуг, в общей численности начавших предпринимательскую деятельность женщин, \%

$$
y_{4}\left(x_{4}\right)=\frac{505,71}{10,32 \times \sqrt{2 \pi}} \cdot e^{\frac{-\left(x_{4}-20,28\right)^{2}}{2 \times 10,32 \times 10,32}}
$$

- удельный вес мужчин, создавших фирмы по оказанию услуг в здравоохранении и образовании, а также социальных услуг, в общей численности начавших предпринимательскую деятельность мужчин, \%

$$
y_{5}\left(x_{5}\right)=\frac{219,14}{4,14 \times \sqrt{2 \pi}} \cdot e^{\frac{-\left(x_{5}-10,60\right)^{2}}{2 \times 4,14 \times 4,14}} ;
$$

- отношение значений показателей, характеризующих удельные веса женщин и мужчин, создавших фирмы по оказанию услуг в здравоохранении и образовании, а также социальных услуг

$$
y_{6}\left(x_{6}\right)=\frac{42,14}{0,82 \times \sqrt{2 \pi}} \cdot e^{-\frac{\left(x_{6}-1,91\right)^{2}}{2 \times 0,82 \times 0,82}} .
$$

Высокое качество функций (1)-(6) было подтверждено в процессе тестирования по критериям Шапиро-Вилка, Пирсона и Колмогорова-Смирнова.

На следующем этапе исследования были выявлены закономерности, характеризующие распределения рассматриваемых показателей. В столбце 2 (табл. 1) приведены данные, характеризующие средние величины показателей. Диапазоны, в которых находятся значения показателей по большинству стран, продемонстрированы в третьем столбце таблицы. 
Значения показателей, характеризующих предпринимателей в сфере услуг

Values of indicators that characterize entrepreneurs in the service sector

\begin{tabular}{|l|c|c|}
\hline \multicolumn{1}{|c|}{ Наименование показателя } & $\begin{array}{c}\text { Средние } \\
\text { величины }\end{array}$ & $\begin{array}{c}\text { 3начения } \\
\text { по большинству } \\
\text { стран }\end{array}$ \\
\hline $\begin{array}{l}\text { удельный вес женщин, создавших фирмы по оказанию финансовых, } \\
\text { профессиональных, административных и потребительских услуг, } \\
\text { в общей численности начавших предпринимательскую } \\
\text { деятельность женщин, }\end{array}$ & 15,14 & $4,65-25,63$ \\
\hline $\begin{array}{l}\text { удельный вес мужчин, создавших фирмы по оказанию финансовых, } \\
\text { профессиональных, административных и потребительских услуг, } \\
\text { в общей численности начавших предпринимательскую } \\
\text { деятельность мужчин, \% }\end{array}$ & 16,96 & $7,33-26,59$ \\
\hline $\begin{array}{l}\text { отношение значений показателей, характеризующих удельные веса } \\
\text { женщин и мужчин, создавших фирмы по оказанию финансовых, } \\
\text { профессиональных, административных и потребительских услуг }\end{array}$ & 0,91 & $0,43-1,39$ \\
\hline $\begin{array}{l}\text { удельный вес женщин, создавших фирмы по оказанию услуг } \\
\text { в здравоохранении и образовании, а также социальных услуг, } \\
\text { в общей численности начавших предпринимательскую } \\
\text { деятельность женщин,\% }\end{array}$ & 20,28 & $9,96-30,6$ \\
\hline $\begin{array}{l}\text { удельный вес мужчин, создавших фирмы по оказанию услуг } \\
\text { в здравоохранении и образовании, а также социальных услуг, } \\
\text { в общей численности начавших предпринимательскую } \\
\text { деятельность мужчин, \% }\end{array}$ & 10,60 & $6,46-14,74$ \\
\hline $\begin{array}{l}\text { отношение значений показателей, характеризующих удельные веса } \\
\text { женщин и мужчин, создавших фирмы по оказанию услуг } \\
\text { в здравоохранении и образовании, а также социальных услуг }\end{array}$ & 1,91 & $1,09-2,73$ \\
\hline
\end{tabular}

Источник. Расчеты проведены автором на основе функций (1)-(6).

Среднее значение удельного веса женщин, создавших фирмы по оказанию финансовых, профессиональных, административных и потребительских услуг, в общей численности начавших предпринимательскую деятельность женщин, достигало в 2018 году более 15,4 \%. Соответствующий показатель по мужчинам был несколько выше - почти 17 \%. То есть почти каждый шестой предприниматель в рассматриваемых странах специализировался на оказании указанных услуг. Превышение удельного веса мужчин, создавших фирмы по оказанию финансовых, профессиональных, административных и потребительских услуг характерно для большинства (37) стран. В 20 странах отмечается превышение показателя по женщинам. В двух странах показатели по женщинам и мужчинам равны. Среднее значение отношения величин указанных показателей составило в 2018 году 0,91. Таким образом, гипотеза 1 о наличии гендерных различий подтвердилась, поскольку в большинстве стран отмечалось превалирование удельного веса фирм, созданных мужчинами.

Среднее значение удельного веса женщин, создавших фирмы по оказанию услуг в здравоохранении и образовании, а также социальных услуг, в общей численности начавших предпринимательскую деятельность женщин, составило в 2018 году более 20,3%. Этим видам услуг отдала предпочтение каждая пятая женщина-предприниматель. Соответствующий показатель по мужчинам был существенно (в 1,9 раза) меньше - почти 10,6 \%. Тенденция превышения указанного показателя по женщинам характерна для большинства (52 стран). Только в 7 странах, а именно Индонезии, Мексике, Панаме, Японии, Эквадоре, Таиланде и Малайзии имело место превышение показателей по мужчинам по сравнению с женщинами. Среднее значение отношения величин показателей составило в 2018 году 1,91. Подтвердилась 
гипотеза 2 о наличии гендерных различий в здравоохранении, образовании и социальных услугах, поскольку в большинстве стран удельный вес женских бизнесов отмечался на более высоком уровне по сравнению с мужскими бизнесами.

Данные таблицы 1 свидетельствуют о том, что в среднем по рассматриваемым странам удельный вес женщин, создавших бизнесы в сфере услуг (по обеим группам фирм), достигал почти 35,4 \%. Фирмы, специализированные на всех рассматриваемых в статье видах услуг, в 2018 году были созданы 27,6 \% от общего количества предпринимателей-мужчин. Интересно отметить, что в сфере сервиса в большинстве рассматриваемых стран в 2018 году среди созданных превалировали женские бизнесы.

Для проверки гипотезы 3 проводился анализ данных, представленных в столбце 3 таблицы 1. Анализ показал существенную дифференциацию по рассматриваемым странам значений каждого из шести показателей. Следовательно, третья гипотеза подтвердилась.

На следующем этапе выявлялись страны, в которых отмечались максимальные и минимальные значения каждого из показателей. При этом к максимальным и минимальным относятся значения, соответственно превышающие верхние границы диапазонов, продемонстрированных в третьем столбце таблицы 1 и меньшие нижних границ диапазонов. Итоги этого анализа приведены в таблице 2. Наряду с перечнями стран в этой таблице представлено также подразделение выявленных стран по их географическому положению и уровню доходов населения.

Таблица 2

Table 2

Страны с максимальными и минимальными значениями показателей

Countries with maximum and minimum indicator values

\begin{tabular}{|c|c|c|}
\hline $\begin{array}{c}\text { Наименование } \\
\text { показателя }\end{array}$ & Максимальные значения & Минимальные значения \\
\hline 1 & 2 & 3 \\
\hline $\begin{array}{l}\text { удельный вес женщин, } \\
\text { создавших фирмы по } \\
\text { оказанию финансовых, } \\
\text { профессиональных, } \\
\text { административных и } \\
\text { потребительских услуг, } \\
\text { в общей численности } \\
\text { начавших } \\
\text { предпринимательскую } \\
\text { деятельность женщин, } \\
\text { \% }\end{array}$ & $\begin{array}{c}\text { Австрия, Великобритания, Эстония, } \\
\text { Швейцария, Хорватия, США, } \\
\text { Люксембург, Кипр, Австралия, } \\
\text { Словения. Расположены в Европе - } \\
\text { восемь стран, по одной стране в } \\
\text { Северной Америке и Австралии. } \\
\text { Доходы населения во всех странах } \\
\text { высокие. }\end{array}$ & $\begin{array}{c}\text { Индонезия, Российская Федерация, } \\
\text { Ангола, Вьетнам, Греция, Таиланд, } \\
\text { Египет, Малайзия, Эквадор, Индия, } \\
\text { Марокко. Две страны расположены в } \\
\text { Европе, в Азии - пять стран, в Африке - } \\
\text { три страны, в Латинской Америке - } \\
\text { одна страна. Высокие доходы } \\
\text { населения отмечаются в одной стране, } \\
\text { средние доходы - в трех странах, } \\
\text { низкие - в семи странах. }\end{array}$ \\
\hline $\begin{array}{l}\text { удельный вес мужчин, } \\
\text { создавших фирмы по } \\
\text { оказанию финансовых, } \\
\text { профессиональных, } \\
\text { административных и } \\
\text { потребительских услуг, } \\
\text { в общей численности } \\
\text { начавших } \\
\text { предпринимательскую } \\
\text { деятельность мужчин, } \\
\text { \% }\end{array}$ & $\begin{array}{c}\text { Словения, Канада, Кипр, Люксембург, } \\
\text { ОАЭ, Израиль, Испания, } \\
\text { Великобритания, } \\
\text { США, Швейцария. Семь стран } \\
\text { расположены в Европе, две страны - } \\
\text { в Азии, в Северной Америке - одна } \\
\text { страна. Доходы населения высокие во } \\
\text { всех странах. }\end{array}$ & $\begin{array}{c}\text { Индонезия, Мадагаскар, Индия, } \\
\text { Малайзия, Марокко, Египет, Бразилия, } \\
\text { Судан, Таиланд, Саудовская Аравия. } \\
\text { Пять стран расположены в Азии, в } \\
\text { Африке - четыре страны, в Латинской } \\
\text { Америке - одна страна. Доходы } \\
\text { населения: высокие (одна страна), } \\
\text { средние (две страны), } \\
\text { низкие (семь стран). }\end{array}$ \\
\hline
\end{tabular}




\begin{tabular}{|c|c|c|}
\hline 1 & 2 & 3 \\
\hline $\begin{array}{l}\text { отношение значений } \\
\text { показателей, } \\
\text { характеризующих } \\
\text { удельные веса женщин } \\
\text { и мужчин, создавших } \\
\text { фирмы по оказанию } \\
\text { финансовых, } \\
\text { профессиональных, } \\
\text { административных и } \\
\text { потребительских услуг }\end{array}$ & $\begin{array}{c}\text { Саудовская Аравия, Ирландия, } \\
\text { Бразилия, Босния и Герцеговина, } \\
\text { Хорватия, Болгария, Мадагаскар. } \\
\text { Четыре страны расположены в } \\
\text { Европе, по одной стране в Азии, } \\
\text { Африке и Латинской Америке. } \\
\text { Доходы населения: высокие (три } \\
\text { страны), средние (три страны), низкие } \\
\text { (одна страна). }\end{array}$ & $\begin{array}{c}\text { Греция, Российская Федерация, } \\
\text { Аргентина, Вьетнам, ОАЭ, Ангола, } \\
\text { Пуэрто-Рико. По две страны } \\
\text { расположены в Европе, Азии и } \\
\text { Латинской Америке, одна страна в } \\
\text { Африке. Высокие доходы имели место } \\
\text { в семи странах, низкие доходы были в } \\
\text { двух странах. }\end{array}$ \\
\hline $\begin{array}{l}\text { удельный вес женщин, } \\
\text { создавших фирмы по } \\
\text { оказанию услуг в } \\
\text { здравоохранении, и } \\
\text { образовании, а также } \\
\text { социальных услуг, в } \\
\text { общей численности } \\
\text { начавших } \\
\text { предпринимательскую } \\
\text { деятельность } \\
\text { женщин,\% } \\
\end{array}$ & $\begin{array}{c}\text { Пуэрто-Рико, Великобритания, } \\
\text { Швеция, Франция, ОАЭ, Германия, } \\
\text { Индия, Нидерланды. Расположены в } \\
\text { Европе пять стран, в Азии - две } \\
\text { страны, в Латинской Америке - одна } \\
\text { страна. Высокие доходы населения в } \\
\text { семи странах, низкие доходы в одной } \\
\text { стране. }\end{array}$ & $\begin{array}{c}\text { Мадагаскар, Малайзия, Эквадор, } \\
\text { Таиланд, Ангола, Гватемала, Мексика, } \\
\text { Вьетнам, Египет. Три страны } \\
\text { расположены в Азии, по три страны - } \\
\text { в Африке и Латинской Америке. } \\
\text { Средние доходы отмечались в четырех } \\
\text { странах, а низкие доходы - } \\
\text { в пяти странах. }\end{array}$ \\
\hline $\begin{array}{l}\text { удельный вес мужчин, } \\
\text { создавших фирмы по } \\
\text { оказанию услуг в } \\
\text { здравоохранении и } \\
\text { образовании, а также } \\
\text { социальных услуг, в } \\
\text { общей численности } \\
\text { начавших } \\
\text { предпринимательскую } \\
\text { деятельность мужчин, } \\
\text { \% }\end{array}$ & $\begin{array}{c}\text { Республика Корея, Пуэрто-Рико, } \\
\text { Ирландия, Франция, Панама, Япония, } \\
\text { Германия, Словацкая Республика, } \\
\text { Австрия, Казахстан. } \\
\text { В Европе расположены пять стран, } \\
\text { три страны - в Азии, две страны - } \\
\text { в Латинской Америке. В девяти } \\
\text { странах доходы населения высокие, } \\
\text { средние доходы - в одной стране. }\end{array}$ & $\begin{array}{c}\text { Мадагаскар, Италия, Египет, Индия, } \\
\text { Кипр, Тайвань, Китай, Гватемала. } \\
\text { В Европе и Африке расположены по } \\
\text { две страны, три страны расположены в } \\
\text { Азии, одна страна - в Латинской } \\
\text { Америке. Доходы населения: высокие } \\
\text { (три страны), средние (две страны), } \\
\text { низкие (три страны). }\end{array}$ \\
\hline $\begin{array}{l}\text { отношение значений } \\
\text { показателей, } \\
\text { характеризующих } \\
\text { удельные веса женщин } \\
\text { и мужчин, создавших } \\
\text { фирмы по оказанию } \\
\text { услуг в } \\
\text { здравоохранении и } \\
\text { образовании, а также } \\
\text { социальных услуг }\end{array}$ & $\begin{array}{c}\text { Испания, ОАЭ, Великобритания, } \\
\text { Аргентина, Нидерланды, Катар, } \\
\text { Швеция, Кипр, Индия, Италия. } \\
\text { В Европе расположены шесть стран, в } \\
\text { Азии - три страны, в Латинской } \\
\text { Америке одна страна. Доходы } \\
\text { населения: высокие (восемь стран), } \\
\text { средние и низкие (одна страна). }\end{array}$ & $\begin{array}{c}\text { Индонезия, Мексика, Панама, Япония, } \\
\text { Эквадор, Таиланд, Малайзия, } \\
\text { Болгария, Ангола, Вьетнам. По одной } \\
\text { стране расположены в Европе и } \\
\text { Африке, в Латинской Америке три } \\
\text { страны, а в Азии - пять стран. } \\
\text { Высокие доходы населения имели } \\
\text { место в двух странах, средние доходы - } \\
\text { в четырех странах, низкие доходы - } \\
\text { в четырех странах. }\end{array}$ \\
\hline
\end{tabular}

Источник. Разработано автором на основе данных таблицы 1 и проекта Глобального мониторинга предпринимательства.

В таблице 2 приведена информация по территориальному расположению стран с высокими (столбец 2) и низкими (столбец 3) значениями каждого из шести оцениваемых в нашем исследовании показателей. Анализ этой информации показал, что связи между значениями показателей и территориальным расположением стран, а также уровнем доходов населения в этих странах, не наблюдается. То есть страны с высокими и низкими значениями показателей расположены в различных частях света. Таким образом, можно констатировать подтверждение гипотезы 4. Гипотеза 5 не нашла подтверждение по странам, в которых 
отмечались максимальные значения удельных весов женщин и мужчин, создавших фирмы по оказанию финансовых, профессиональных, административных и потребительских услуг. Все указанные страны характеризовались только высоким уровнем доходов населения. По остальным странам гипотеза 5 подтвердилась.

Сравнительный анализ значений рассматриваемых показателей по России и зарубежным странам продемонстрировал следующее:

- значение показателя 1 составляет 2,5 \%, что существенно в 6,1 раза меньше средней величины по зарубежным странам;

- значение показателя 2 составляет 15,5 \%, что в 1,1 раза меньше средней величины по зарубежным странам;

- значение показателя 3 составляет 0,2, что в 4,6 раза меньше средней величины по зарубежным странам;

- значение показателя 4 составляет 20,0 \%, что совпадает со средней величиной по зарубежным странам;

- значение показателя 5 составляет $11,3 \%$, что в 1,1 раза больше средней величины по зарубежным странам;

- значение показателя 6 составляет 1,77, что в 1,1 раза меньше средней величины по зарубежным странам.

Таким образом, в России как женщины, так и мужчины реже, по сравнению с зарубежными странами, создают фирмы по оказанию финансовых, профессиональных, административных и потребительских услуг. Это, на наш взгляд, логично, поскольку указанные частные фирмы в этих видах деятельности начали создаваться в нашей стране относительно недавно. По фирмам, созданным женщинами и относящимся ко второй группе, в нашей стране наблюдается паритет с зарубежными странами. А по аналогичным фирмам, созданным мужчинами, имеет место небольшое превышение по сравнению со средним уровнем в зарубежных странах.

\section{Заключение}

Цель исследования, заключавшаяся в оценке уровней участия предпринимателей в сфере услуг в современных национальных экономиках по данным за 2018 год, была достигнута. К выводам, обладающим научной новизной и оригинальностью, относятся:

1. Приведена методика оценки показателей, описывающих создание фирм в сфере услуг женщинами и мужчинами.

2. Проведено моделирование распределения шести показателей, характеризующих оказание услуг предпринимателями по 59 странам.

3. Доказано, что около 30 \% фирм, созданных предпринимателями, специализируются на оказании двух основных групп услуг.

4. Показано, что в большинстве стран имеют место гендерные различия в удельных весах сервисных фирм.

5. В 2018 году имели место существенные различия в значениях шести рассматриваемых показателей по странам.

6. Выявлены страны, для которых были характерны максимальные и минимальные значения этих шести показателей.

7. Проведено сопоставление значений показателей по России и зарубежным странам.

Полученные результаты исследования имеют определенное теоретическое и прикладное значение. Предложенные показатели и модели их расчета могут быть использованы при обосновании программ развития предпринимательства правительством, региональными и муниципальными органами власти. Итоги расчетов представляют интерес для начинающих предпринимателей. Новые знания о предпринимательской специализации в сфере услуг могут использоваться в деятельности образовательных учреждений. 


\section{Список литературы}

1. Aidis R., Weeks J. 2016. Mapping the Gendered Ecosystem: The Evolution of Measurement Tools for Comparative High-Impact Female Entrepreneur Development. International Journal of Gender and Entrepreneurship, 8 (4): 330-352.

2. Black A.D., Car J., Pagliari C., Anandan C., Cresswell K. 2011. The Impact of eHealth on the Quality and Safety of Health Care: A Systematic Overview. PLoS Med, 8 (1): 1-16.

3. Castaldi C. 2009. The relative weight of manufacturing and services in Europe: An innovation perspective. Technological Forecasting and Social Change, 76 (6): 709-722.

4. Castillo R., Flores C., Rodrigue M. 2014. The Relative Importance of the Service Sector in the Mexican Economy: A Time Series Analysis Lecturas de Economa, 80: 133-151.

5. Chhabra M., Karmarkar Y. 2016. Gender gap in entrepreneurship - a study of small and micro enterprises. ZENITH International Journal of Multidisciplinary Research, 6 (8): 82-99.

6. Cuadrado R. 2013. Service industries and regions, growth, location and regional effects. Springer. Berlin. Germany. 450 p.

7. Cruz R., Delfina M. 2004. Desigualdad Salarial y Desplazamientos de la Demanda Calificada en México, 1993-1999. Trimestre Económico, 71 (289): 625-680.

8. Eichengreen B., Gupta P. 2013. The two waves of service sector growth. Oxford Economic Papers, 65 (1): $96-123$.

9. Fuentes N.A. 2005. Construcción de una Matriz Regional de InsumoProducto. Problemas del Desarrollo, 36 (140): 89-112.

10. Fukao K. 2010. Service Sector Productivity in Japan: The key to future economic growth. RIETI Policy Discussion Paper Series 10-P-007. August.

11. Global Entrepreneurship Monitor 2018/2019. 2019. Women's Entrepreneurship Report. Global Entrepreneurship Research Association (GERA). London Business School, London, United Kingdom.

12. Grosser K., Moon J. 2019. CSR and feminist organization studies: towards an integrated theorization for the analysis of gender issues. Journal of Business Ethics, 155 (2): 321-342.

13. Jennings J.E., Brush C.G. 2013. Research on women entrepreneurs: challenges to (and from) the broader entrepreneurship literature? The Academy of Management Annals, 7 (1): 663-715.

14. June S., Khar K.Y. 2014. Innovative work behavior (IWB) in the knowledge intensive business services (KIBS) sector in Malaysia: The effect of leader-member exchange (LMX) and social capital (SC). Asian Social Science, 10 (2): 172-182.

15. Liao J. 2020. The rise of the service sector in China. China Economic Review, 59: 1-22.

16. Mugwati M.Z., Nkala D., Mukanganiki C. 2013. The composition and regulation of the financial services sector in Zimbabwe. Asian Economic and Financial Review, 3 (4): 483-489.

17. Nordenflycht A. 2010. What is a Professional Service Firm? Towards a Theory and Taxonomy of Knowledge Intensive Firms. Academy of Management Review, 35 (1): 155-174.

18. Pinkovetskaia I., Slepova V. 2018. Estimation of Fixed Capital Investment in SMEs: the Existing Differentiation in the Russian Federation. Business Systems Research, 9 (1): 65-78.

19. Spatscheck C. 2019. Spatial approaches to social work - theoretical foundations and implications for practice and research. European Journal of Social Work, 22 (5): 845-859.

20. Sperber S., Linder C. 2018. Gender-specifics in startup strategies and the role of the entrepreneurial ecosystem. Small Business Economics, 53 (4): 1-14.

\section{References}

1. Aidis R., Weeks J. 2016. Mapping the Gendered Ecosystem: The Evolution of Measurement Tools for Comparative High-Impact Female Entrepreneur Development. International Journal of Gender and Entrepreneurship, 8 (4): 330-352.

2. Black A.D., Car J., Pagliari C., Anandan C., Cresswell K. 2011. The Impact of eHealth on the Quality and Safety of Health Care: A Systematic Overview. PLoS Med, 8 (1): 1-16.

3. Castaldi C. 2009. The relative weight of manufacturing and services in Europe: An innovation perspective. Technological Forecasting and Social Change, 76 (6): 709-722.

4. Castillo R., Flores C., Rodrigue M. 2014. The Relative Importance of the Service Sector in the Mexican Economy: A Time Series Analysis Lecturas de Economa, 80: 133-151.

5. Chhabra M., Karmarkar Y. 2016. Gender gap in entrepreneurship - a study of small and micro enterprises. ZENITH International Journal of Multidisciplinary Research, 6 (8): 82-99. 
6. Cuadrado R. 2013. Service industries and regions, growth, location and regional effects. Springer. Berlin. Germany. $450 \mathrm{p}$.

7. Cruz R., Delfina M. 2004. Desigualdad Salarial y Desplazamientos de la Demanda Calificada en México, 1993-1999. Trimestre Económico, 71 (289): 625-680.

8. Eichengreen B., Gupta P. 2013. The two waves of service sector growth. Oxford Economic Papers, 65 (1): $96-123$.

9. Fuentes N.A. 2005. Construcción de una Matriz Regional de InsumoProducto. Problemas del Desarrollo, 36 (140): 89-112.

10. Fukao K. 2010. Service Sector Productivity in Japan: The key to future economic growth. RIETI Policy Discussion Paper Series 10-P-007. August.

11. Global Entrepreneurship Monitor 2018/2019. 2019. Women's Entrepreneurship Report. Global Entrepreneurship Research Association (GERA). London Business School, London, United Kingdom.

12. Grosser K., Moon J. 2019. CSR and feminist organization studies: towards an integrated theorization for the analysis of gender issues. Journal of Business Ethics, 155 (2): 321-342.

13. Jennings J.E., Brush C.G. 2013. Research on women entrepreneurs: challenges to (and from) the broader entrepreneurship literature? The Academy of Management Annals, 7 (1): 663-715.

14. June S., Khar K.Y. 2014. Innovative work behavior (IWB) in the knowledge intensive business services (KIBS) sector in Malaysia: The effect of leader-member exchange (LMX) and social capital (SC). Asian Social Science, 10 (2): 172-182.

15. Liao J. 2020. The rise of the service sector in China. China Economic Review, 59: 1-22.

16. Mugwati M.Z., Nkala D., Mukanganiki C. 2013. The composition and regulation of the financial services sector in Zimbabwe. Asian Economic and Financial Review, 3 (4): 483-489.

17. Nordenflycht A. 2010. What is a Professional Service Firm? Towards a Theory and Taxonomy of Knowledge Intensive Firms. Academy of Management Review, 35 (1): 155-174.

18. Pinkovetskaia I., Slepova V. 2018. Estimation of Fixed Capital Investment in SMEs: the Existing Differentiation in the Russian Federation. Business Systems Research, 9 (1): 65-78.

19. Spatscheck C. 2019. Spatial approaches to social work - theoretical foundations and implications for practice and research. European Journal of Social Work, 22 (5): 845-859.

20. Sperber S., Linder C. 2018. Gender-specifics in startup strategies and the role of the entrepreneurial ecosystem. Small Business Economics, 53 (4): 1-14.

\section{ИНФОРМАЦИЯ ОБ АВТОРЕ}

Пиньковецкая Юлия Семеновна, кандидат экономических наук, доцент, доцент кафедры экономического анализа и государственного управления Ульяновского государственного университета, Ульяновск, Россия

\section{INFORMATION ABOUT THE AUTHOR}

Iuliia S. Pinkovetskaia, Candidate of Economic Sciences, Associate Professor, Associate Professor of the Department of Economic analysis and state management Ulyanovsk State University, Ulyanovsk, Russian 